\title{
Determinação de constituintes inorgânicos em méis de abelha coletados no estado de Sergipe por espectrometria de absorção atômica com chama (AAS)
}

Determination of inorganic constituents in bee honey collected in the state of Sergipe for flame atomic absorption spectrometry (F-AAS)

\author{
M. C. Almeida ${ }^{1}$; C. A. B. Garcia ${ }^{1 *}$ H. L. Garcia ${ }^{2}$; A. C. S. Andrade'; M. R. R. \\ Souza ${ }^{1}$ \\ ${ }^{1}$ Departamento de Química/Laboratório de Química Analítica Ambiental/Universidade Federal de Sergipe, 49100-000, \\ São Cristóvão-Sergipe, Brasil \\ ${ }^{1}$ Departamento de Engenharia Química/Laboratório de Operações Unitárias/ Universidade Federal de Sergipe, \\ 49100-000, São Cristóvão-Sergipe, Brasil \\ *cgarcia@ufs.br
}

(Recebido em 12 de outubro de 2015; aceito em 28 de abril de 2016)

\begin{abstract}
A procura por produtos naturais e saudáveis cresceu de forma significante não só no Brasil como em toda parte do mundo, o que conduziu à busca pela qualidade e segurança alimentar de produtos como o mel. Neste sentido, o objetivo deste trabalho foi pesquisar o teor de constituintes inorgânicos ( $\mathrm{Na}, \mathrm{K}, \mathrm{Ca}, \mathrm{Co}, \mathrm{Fe}$, $\mathrm{Ni}, \mathrm{Mg}, \mathrm{Mn}$ e $\mathrm{Pb}$ ) em mel de abelhas Apis mellifera provenientes de quatro municípios do Estado de Sergipe: Poço Redondo, Japaratuba, Porto da Folha e Barra dos Coqueiros e estabelecer se estes minerais estão fora dos valores máximos permitidos. Os analitos foram determinados por espectrometria de absorção atômica (E.A.A.). Os valores para os minerais foram: $\mathrm{Fe}\left(9,35-49,82 \mathrm{mg} \mathrm{kg}^{-1}\right)$, Mn $\left(0,71-5,80 \mathrm{mg} \mathrm{kg}^{-1}\right)$, $\mathrm{Mg}\left(7,82\right.$ - 112,63 mg kg-1), K (266,34 - 1.299,39 $\left.\mathrm{mg} \mathrm{kg}^{-1}\right), \mathrm{Na}\left(14,21-174,84 \mathrm{mg} \mathrm{kg}^{-1}\right)$ e Ca $(20,04-$ $\left.81,71 \mathrm{mg} \mathrm{kg}^{-1}\right)$. Ressalta-se que estas concentrações apresentam-se dentro dos valores máximos recomendados na legislação nacional e internacional vigente. Também foi possível fornecer subsídios aos apicultores e técnicos a respeito das características específicas do mel, como produto natural único.

Palavras-chave: Mel de abelha, minerais, Espectrometria de Absorção Atômica
\end{abstract}

The demand for natural and healthy products has grown significantly, which have led to the search for quality and food safety of products such as honey. The objective of this study was to investigate the content of inorganic constituents ( $\mathrm{Na}, \mathrm{K}, \mathrm{Ca}, \mathrm{Co}, \mathrm{Fe}, \mathrm{Ni}, \mathrm{Mg}, \mathrm{Mn}$ and $\mathrm{Pb}$ ) present in bees' honey, Apis mellifera, which are from four municipalities in the state of Sergipe - Poço Redondo, Japaratuba, Porto da Folha and Barra dos Coqueiros, establishing whether these minerals are outside the maximum allowable values. The analytes were determined by Atomic Absorption Spectrometry (AAS). The values for the minerals were $\mathrm{Fe}$ (9.35 - $\left.49.82 \mathrm{mg} \mathrm{kg}^{-1}\right), \mathrm{Mn}\left(0.71-5.80 \mathrm{mg} \mathrm{kg}^{-1}\right), \mathrm{Mg}\left(7.82-112.63 \mathrm{mg} \mathrm{kg}^{-1}\right), \mathrm{K}\left(266.34-1299.39 \mathrm{mg} \mathrm{kg}^{-}\right.$ $\left.{ }^{1}\right), \mathrm{Na}\left(14.21-174.84 \mathrm{mg} \mathrm{kg}^{-1}\right)$ and $\mathrm{Ca}\left(20.04-81.71 \mathrm{mg} \mathrm{kg}^{-1}\right)$. All of them have presented themselves within the maximum recommended levels in current national and international laws. It was also possible for this study to provide subsidies to beekeepers and technicians about the specific properties of honey, as unique natural product.

Keywords: Honey, minerals, Flame Atomic Absorption Spectrometry.

\section{INTRODUÇÃO}

A procura por produtos naturais tem gerado uma demanda crescente por produtos apícolas e, ao mesmo tempo, uma maior agregação do mel na alimentação humana. O mel têm se destacado não apenas por suas propriedades terapêuticas, mas também como suplemento alimentar sem a adição de outras substâncias durante a sua elaboração. A simples análise do mel demonstra, de forma clara, a riqueza nutritiva de sua composição, o que inclui micronutrientes como vitaminas e minerais [1].

O mel é um alimento natural, produzido por abelhas melíferas, a partir do néctar de flores (floral), de secreções procedentes de partes vivas de plantas ou de excreções de insetos sugadores de plantas (melato) que as abelhas recolhem, transformam, combinam com substâncias 
específicas próprias e deixam maturar nos favos da colmeia [2]. Este produto natural é constituído, em sua maioria, por hidratos de carbono (glicose e frutose), água, minerais $(\mathrm{Ca}, \mathrm{Cu}$, $\mathrm{Fe}, \mathrm{Mg}, \mathrm{P}, \mathrm{K}$, entre outros), aminoácidos, ácidos orgânicos (ácido acético, ácido cítrico, entre outros), vitaminas do complexo B, vitaminas $\mathrm{C}, \mathrm{D}$ e $\mathrm{E}$ e apresenta um teor considerável de antioxidantes (flavonóides e compostos fenólicos). Devido ao seu teor em açúcares simples, de assimilação rápida, o mel é altamente calórico (cerca de $3,4 \mathrm{kcal} \mathrm{g}^{-1}$ ), sendo uma valiosa fonte de energia $[3,4,28]$.

As abelhas são consideradas organismos bioindicadores que servem como medida para informar as condições ambientais de um determinado local. Como o mel é o resultado de um processo de bioacumulação, este pode ser usado para recolher informações do ambiente de convívio das abelhas em uma área maior que $7 \mathrm{~km}^{2}$. Assim, as concentrações dos elementos químicos presentes no mel refletem as quantidades presentes em toda a região, atribuindo a este produto status de bom indicador biológico de poluição ambiental [3, 5-6].

Os metais tóxicos, presentes na atmosfera podem se depositar no pêlo das abelhas e, como consequência, serem transportados para as colmeias juntamente com o pólen, podendo ainda ser absorvidos juntamente com o néctar das flores ou trazidos pela água ou melato [7].

Além do monitoramento ambiental, a determinação de espécies inorgânicas potencialmente tóxicas no mel também é interessante para o controle da qualidade e dos aspectos nutricionais. Já a determinação dos elementos químicos considerados essenciais à dieta humana é importante para classificar o mel como uma fonte rica destes minerais [8]. Alguns trabalhos relatam os níveis de concentração de metais (valores médios encontrados em mg kg$\left.{ }^{-1}\right)$ em mel de abelha para o $\mathrm{Al}(1,5$ $\pm 0,28), \mathrm{Ba}(1,18 \pm 0,01), \mathrm{Cr}(0,40 \pm 0,02), \mathrm{Cu}( \pm 2,60,44), \mathrm{Fe}(2,33 \pm 0,30), \mathrm{Mn}(3,52 \pm 0,21), \mathrm{Ni}$ $(4,47 \pm 0,15), \mathrm{Ti}(0,48 \pm 0,04), \mathrm{Pb}(0,88 \pm 0,20), \mathrm{K}(346,80 \pm 20,0), \mathrm{Ca}(34,55 \pm 1,0), \mathrm{Mg}(13,47$ $\pm 1,65), \mathrm{Na}(53,55 \pm 1,5), \mathrm{Co}(2,10 \pm 0,23), \mathrm{Sr}(0,42 \pm 0,06)$ e Zn $(0,16 \pm 2,4)$ [9-12].

No entanto, com a variedade de floradas e com um mercado cada vez mais exigente, poucos registros da composição mineral do mel brasileiro são encontrados na literatura. Os poucos trabalhos envolvendo mel brasileiro e suas composições minerais utilizam a técnica de emissão atômica, visando um conhecimento abrangente de um grande número de constituintes, relacionado à origem e autenticidade do mel. Entretanto, a técnica de absorção atômica também pode ser bastante útil, uma vez que apresenta características importantes como seletividade, sensibilidade, baixos limites de detecção, repetibilidade e reprodutibilidade [13-15]. Os alimentos derivados do mel são regulamentados pelo Codex Alimentarius, pelo Mercosul e pela legislação brasileira que estabelecem níveis máximos de contaminantes metálicos em função de sua toxicidade e tolerância cumulativa no organismo humano [16-19].

Neste contexto, esse trabalho teve como objetivo avaliar a concentração de constituintes inorgânicos sódio, potássio, cálcio, cobalto, ferro, níquel, magnésio, manganês e chumbo em mel de abelhas Apis mellifera provenientes de quatro municípios do Estado de Sergipe (Poço Redondo, Japaratuba, Porto da Folha e Barra dos Coqueiros), visando a comparação dos níveis destes constituintes com os valores máximos recomendados nas legislações vigentes, a fim de fornecer subsídios aos apicultores e técnicos a respeito das características específicas do mel, como produto natural único.

\section{MATERIAL E MÉTODOS}

\section{Reagentes, soluções e curvas analíticas}

Ácido nítrico $(65 \% \mathrm{v} / \mathrm{v})$ e Peróxido de hidrogênio $(30 \% \mathrm{v} / \mathrm{v})$ foram adquiridos da Merck (Alemanha). Todas as soluções foram preparadas com água ultra-pura $(18 \mathrm{M} \Omega \mathrm{cm}$, Milipore, USA). As soluções padrão de $\mathrm{Na}, \mathrm{K}, \mathrm{Ca}, \mathrm{Co}, \mathrm{Fe}, \mathrm{Ni}, \mathrm{Mg}, \mathrm{Mn}$ e $\mathrm{Pb}$, foram preparadas a partir de soluções estoques de $1000 \mathrm{mg} \mathrm{L}^{-1}$ (Tritisol ${ }^{\circledR}$ Merck, Alemanha) com 1,000 $\pm 0,002 \mathrm{~g}$ do metal. As soluções diluídas (em água ultra pura) usadas na obtenção das curvas analíticas foram preparadas no momento da análise, a partir das soluções estoque. 


\section{Equipamentos}

Os equipamentos utilizados foram: Espectrofotômetro de Absorção Atômica (E.A.A.), marca Shimadzu, modelo AA-6800, equipado com atomizador por chama e corretor de backgraund BGC-D $_{2}$ e Lâmpadas de catodo oco de Na, K, Ca, Co, Fe, Ni, Mg, Mn e Pb. Os comprimentos de onda (nm) usados nas análises dos metais foram: Na (357,9 nm); K (324,8 nm); Ca (213,9 nm); Co $(240,1 \mathrm{~nm}) ; \mathrm{Fe}(248,3 \mathrm{~nm})$; $\mathrm{Ni}(232,0 \mathrm{~nm}) ; \mathrm{Mg}(285,4 \mathrm{~nm}) ; \mathrm{Mn}(279,5 \mathrm{~nm})$ e Pb $(283,3 \mathrm{~nm})$. Todas determinações foram feitas em chama ar/acetileno. Todos os ajustes instrumentais foram os recomendados no manual do fabricante; Forno de micro-ondas de cavidade fechada com rotor segmentado de média pressão para 18 vasos, dispositivo automático de controle de temperatura em vaso de referência e sensor químico (Milestone, modelo ETHUS PLUS T-800); Balança Analítica digital (Mettler, modelo Toledo AB204-5) e Ultra purificador de água (Millipore, modelo Milli-Q plus).

\section{Coleta das amostras}

Foram coletadas 40 amostras de mel multiflorais produzidos por abelhas africanizadas (Apis mellifera L.) Foram realizadas duas campanhas de amostragem, 20 amostras no mês junho e outras 20 amostras no mês de dezembro, sendo colhidas por apicultores locais em cinco colônias distintas localizadas em quatro municípios do Estado de Sergipe: Poço Redondo (povoado Barra da Onça - 09³8'58.38"S; 36 54'15.71"O), Japaratuba (povoado Caraíbas - 10²5'33.97"S; $36^{\circ} 53^{\prime} 14.29 " \mathrm{O}$ ), Porto da Folha (povoado Lagoa do Rancho - 9 ${ }^{\circ} 58^{\prime} 49.93^{\prime \prime S}$; 37 $26^{\prime} 0.72^{\prime \prime O}$ ) e Barra dos Coqueiros (povoado Capuã - $10^{\circ} 51^{\prime} 10^{\prime \prime} \mathrm{S} ; 36^{\circ} 59^{\prime} 45^{\prime \prime} \mathrm{O}$ ). Estas regiões foram escolhidas por apresentarem diferentes níveis de desenvolvimento urbano-agro-industrial, estando mais ou menos susceptíveis a poluição atmosférica e ambiental.

O município de Barra dos Coqueiros fica localizado na Região Metropolitana de Aracaju e liga-se a capital sergipana pela ponte Aracaju - Barra dos Coqueiros. Nele se localiza o mais importante porto de Sergipe, o Terminal Marítimo Inácio Barbosa. O porto opera cargas gerais como madeira, coque, ureia, trigo, fertilizante e sucos naturais e é, ainda, utilizado pela Petrobrás para apoio às atividades de exploração e produção de petróleo na costa de Sergipe. Japaratuba está localizado a $54 \mathrm{~km}$ de Aracaju e as suas principais atividades econômicas são a agricultura (cana-de-açúcar, mandioca e coco), pedreiras e extração de petróleo. O município de Poço Redondo está inserido dentro da região semi-árida do Nordeste do Brasil, distante $186 \mathrm{~km}$ da capital sergipana. Essa região foi escolhida devido ao aumento das áreas destinadas à pecuária com substituição da criação de caprino pelo gado leiteiro, uso de tecnologias agrícolas ultrapassadas como a queimada, uso de agrotóxicos, e principalmente, o desmatamento indiscriminado da vegetação. Porto da Folha fica a $190 \mathrm{~km}$ de Aracaju e nos últimos anos vêm crescendo economicamente de forma bastante acelerada, sendo suas principais fontes de economia a agricultura, pecuária e turismo. O Povoado Lagoa do Rancho se destaca pela pecuária, produção de leite e seus derivados, apicultura (através da Casa do Mel) e a agricultura.

As amostras de mel foram obtidas diretamente dos favos, utilizando espátulas e facas de plástico. Cada amostra de mel foi colocada em potes plásticos assépticos de $300 \mathrm{~mL}$ devidamente identificados, logo após foram encaminhadas para o Laboratório de Química Analítica Ambiental (LQA) da Universidade Federal de Sergipe (UFS). Durante a permanência na UFS, todas as amostras foram protegidas da luz e mantidas em temperatura ambiente.

\section{Limpeza de materiais}

Todo material do laboratório foi imerso em solução de detergente por pelo menos 3 horas. Em seguida, este foi enxaguado com água corrente e depois água destilada por 3 vezes. Todas as vidrarias usadas foram colocadas em solução de ácido nítrico a $10 \%$ (v/v) por um período de $24 \mathrm{~h}$ e em seguida foram enxaguados, no mínimo, três vezes em água ultrapura. Com relação à limpeza dos vasos de Teflon do forno de micro-ondas, após cada experimento, seguiu-se o procedimento indicado no manual do usuário da Milestone, consistindo em adicionar $5 \mathrm{~mL}$ de $\mathrm{HNO}_{3} 65 \%$ (v/v) 
em cada vaso, e em seguida executar um programa de aquecimento de 10 min a 650 Watt. Após o resfriamento de $25 \mathrm{~min}$, os vasos foram abertos e enxaguados três vezes com água ultra pura.

\section{Digestão em forno de micro-ondas}

Transferiu-se 0,25 g de amostra de mel para os vasos de teflon do forno de micro-ondas. Em seguida adicionou-se $0,25 \mathrm{~mL} \mathrm{H}_{2} \mathrm{O}_{2} 30 \%$ (v/v) e $1 \mathrm{~mL}$ de $\mathrm{HNO}_{3} 65 \% \mathrm{~m} / \mathrm{v}$, deixando este sistema em repouso durante 30 minutos para que a amostra fosse completamente umedecida e que houvesse a liberação de gases; evitando um aumento brusco de pressão durante o aquecimento no forno de micro-ondas. Após a digestão fria, os vasos foram colocados na cavidade do forno de micro-ondas e submetidos aos programas de aquecimento: etapas 1 ( $250 \mathrm{~W}$ por $2 \mathrm{~min}$ ); 2 (250 W por $6 \mathrm{~min}) ; 3$ (400 W por $4 \mathrm{~min}) ; 4(500 \mathrm{~W}$ por $8 \mathrm{~min}) ; 5$ (0 W por $10 \mathrm{~min})$. Depois da digestão, as soluções das amostras e dos brancos foram transferidas para balões volumétricos de $50 \mathrm{~mL}$ e o volume foi aferido com água ultra pura. Todo processo foi realizado em triplicata.

\section{Condições do Espectrômetro de Absorção Atômica}

Os analitos $\mathrm{Na}, \mathrm{K}, \mathrm{Ca}, \mathrm{Co}, \mathrm{Fe}, \mathrm{Ni}, \mathrm{Mg}, \mathrm{Mn}$ e $\mathrm{Pb}$ foram determinados por espectrometria de absorção atômica em chama ar/acetileno utilizando condições analíticas e operacionais estabelecidas pela metodologia oficial [29] (Tabela 1).

Tabela 1: Condições analíticas e operacionais do FAAS.

\begin{tabular}{|c|c|c|c|c|c|c|c|c|}
\hline & $\begin{array}{c}\text { Corrente } \\
(\mathbf{m A})\end{array}$ & $\begin{array}{c}\lambda \\
(\mathbf{n m})\end{array}$ & $\begin{array}{c}\text { Fenda } \\
(\mathbf{n m})\end{array}$ & BCG-D 2 & $\begin{array}{c}\text { Altura } \\
\text { Burner } \\
(\mathbf{m m})\end{array}$ & $\begin{array}{c}\text { Ângulo } \\
\text { Burner } \\
\left({ }^{\circ}\right)\end{array}$ & $\begin{array}{c}\text { Fluxo } \\
\text { gás } \\
\text { (L/min) }\end{array}$ & Oxidante \\
\hline Ca & 8 & 213,9 & 0,5 & Sim & 7 & 0 & 2,0 & $\mathrm{Ar}$ \\
\hline Co & 12 & 240,1 & 0,2 & Sim & 7 & 0 & 2,2 & $\mathrm{Ar}$ \\
\hline $\mathbf{F e}$ & 12 & 248,3 & 0,2 & Sim & 7 & 0 & 2,2 & $\mathrm{Ar}$ \\
\hline $\mathbf{K}$ & 6 & 324,8 & 0,5 & Sim & 7 & 0 & 1,8 & $\mathrm{Ar}$ \\
\hline Mg & 10 & 285,4 & 0,5 & Sim & 7 & 0 & 1,8 & $\mathrm{Ar}$ \\
\hline Mn & 10 & 279,5 & 0,2 & Sim & 7 & 0 & 2,0 & $\mathrm{Ar}$ \\
\hline $\mathrm{Na}$ & 10 & 357,9 & 0,5 & Sim & 9 & 0 & 2,8 & $\mathrm{Ar}$ \\
\hline $\mathbf{N i}$ & 12 & 232,0 & 0,2 & Sim & 7 & 0 & 2,2 & $\mathrm{Ar}$ \\
\hline $\mathbf{P b}$ & 10 & 283,3 & 0,5 & Sim & 7 & 0 & 2,0 & $\mathrm{Ar}$ \\
\hline
\end{tabular}

\section{RESULTADOS E DISCUSSÃO}

\section{Análise dos metais}

Ao analisar os constituintes inorgânicos Sódio (Na), Potássio (K), Cálcio (Ca), Ferro (Fe), Manganês (Mn) e Magnésio (Mg), obteve-se os resultados apresentados na Tabela 2. 
Tabela 2: Concentrações (em $\mathrm{mg} / \mathrm{kg}$ ) dos minerais nas amostras de mel produzidas nos quatro municípios provenientes do Estado de Sergipe - Poço Redondo (povoado Barra da Onça), Japaratuba (povoado Caraíbas), Barra dos Coqueiros (povoado Capuã) e Porto da Folha (povoado Lagoa do Rancho)

\begin{tabular}{ccccccc}
\hline POVOADOS & Ferro & Manganês & Magnésio & Potássio & Sódio & Cálcio \\
\hline Poço Redondo & $12,54 \pm 0,60$ & $1,03 \pm 0,08$ & $7,82 \pm 0,56$ & $266,34 \pm 18,50$ & $14,21 \pm 0,32$ & $33,68 \pm 2,83$ \\
Japaratuba & $19,69 \pm 1,36$ & $2,12 \pm 0,15$ & $57,10 \pm 1,38$ & $660,56 \pm 28,56$ & $17,99 \pm 0,99$ & $42,30 \pm 1,81$ \\
Barra dos & $49,82 \pm 1,05$ & $5,80 \pm 0,23$ & $112,63 \pm 7,61$ & $1299,39 \pm 92,24$ & $174,84 \pm 8,77$ & $81,71 \pm 5,41$ \\
Coqueiros & & & & & & \\
Porto da Folha & $9,35 \pm 0,35$ & $0,71 \pm 0,08$ & $16,79 \pm 0,95$ & $455,6 \pm 18,67$ & $43,32 \pm 2,12$ & $20,04 \pm 1,13$ \\
\hline
\end{tabular}

Os resultados correspondem à média \pm desvio-padrão de cinco análises.

A composição mineral do mel varia de acordo com a origem floral, clima, solo e fatores relativos às abelhas [20-21]. Por isso, os valores dos minerais das amostras não foram homogêneos em virtude dos méis serem multiflorais e, ainda, apresentaram intervalos de variação relativamente altos. Os valores mínimos e máximos para os minerais foram: $\mathrm{Fe}(9,35$ - 49,82 mg $\left.\mathrm{kg}^{-1}\right), \mathrm{Mn}\left(0,71-5,80 \mathrm{mg} \mathrm{kg}^{-1}\right), \mathrm{Mg}\left(7,82-112,63 \mathrm{mg} \mathrm{kg}^{-1}\right), \mathrm{K}\left(266,34-1.299,39 \mathrm{mg} \mathrm{kg}^{-1}\right), \mathrm{Na}$ $\left(14,21-174,84 \mathrm{mg} \mathrm{kg}^{-1}\right)$ e Ca $\left(20,04-81,71 \mathrm{mg} \mathrm{kg}^{-1}\right)$. O elemento mais abundante para todas as amostras foi o Potássio (Figura 1). Em trabalho de Garcia et al. (2011) [25], no qual de avaliou metais em mel de abelhas comercializados no Município de Aracaju/SE, o K é o segundo mais abundante com o valor médio de $304,8 \mathrm{mg} \mathrm{kg}^{-1}$.

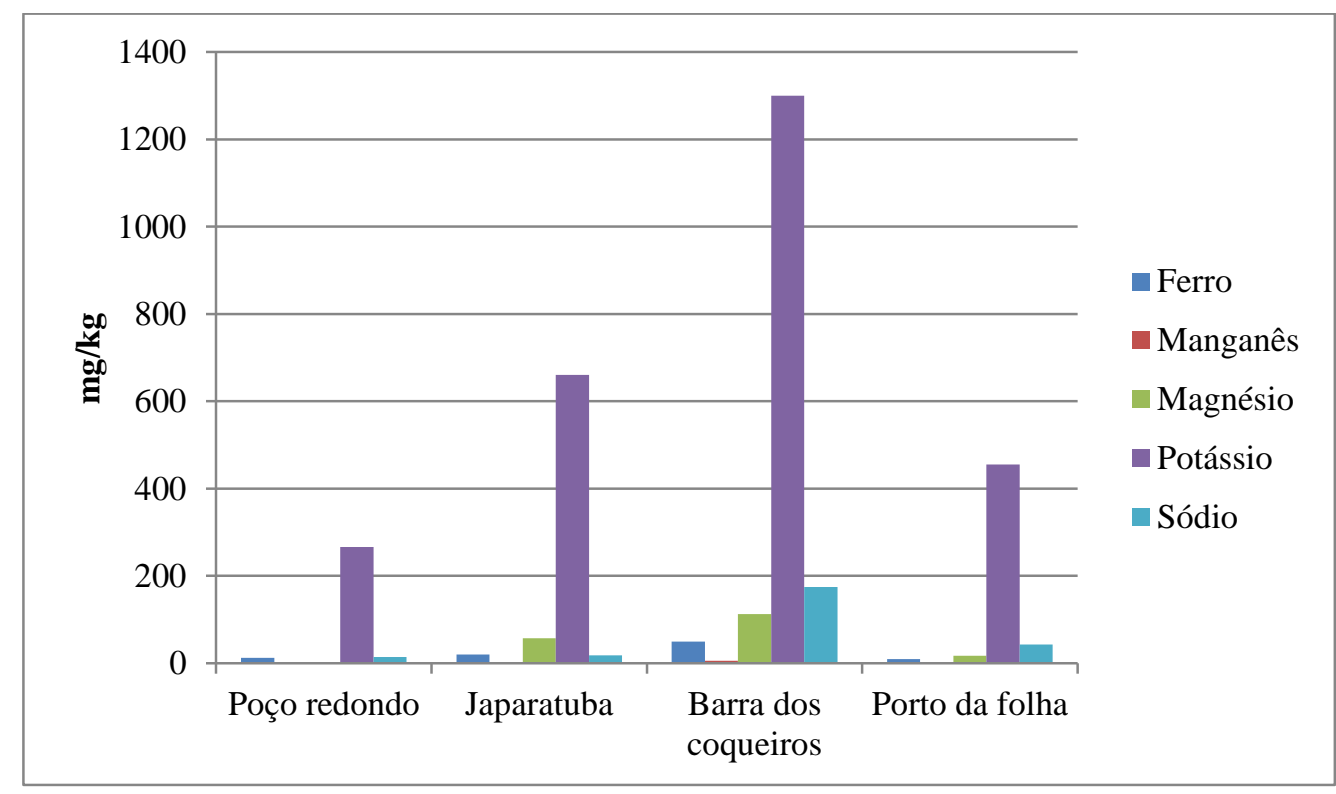

Figura 1: Valores médios encontrados para os elementos essenciais ( $\mathrm{Fe}, \mathrm{Mn}, \mathrm{Mg}, \mathrm{K}, \mathrm{Na}$ ).

Na posição oposta às concentrações de Potássio encontra-se o Manganês, com as menores concentrações entre os minerais analisados. Porém, nos municípios de Barra dos Coqueiros e Japaratuba, as concentrações apresentaram resultados ligeiramente altos em comparação aos outros $\left(2,12\right.$ e $\left.5,8 \mathrm{mg} \mathrm{kg}^{-1}\right)$, fato que pode está relacionado à aplicação de fertilizantes na região durante o período de coleta das amostras. Para o Mn, não há referência de Limite Máximo 
Permitido (LMP) na legislação brasileira. Entretanto, a dose diária recomendada para um adulto é de 2 a $3 \mathrm{mg} / \mathrm{dia}$ [22], possibilitando ao mel sergipano ser usado como fonte nutritiva de $\mathrm{Mn}$.

Em relação aos resultados do Ferro é importante ressaltar que, mesmo não havendo parâmetros pré-estabelecidos na legislação nacional, os valores obtidos com as amostras dos municípios de Japaratuba e Barra dos Coqueiros ultrapassam os limites máximos padronizados pelo CODEX para alimentos, doces e mel (> $15 \mathrm{mg} \mathrm{kg}^{-1}$ ) [23]. As principais fontes de poluição de $\mathrm{Fe}$ são indicadas pela corrosão de metais e escavações. Na Barra dos Coqueiros, as altas concentrações de Fe podem estar relacionadas à proximidade das colônias com o litoral, região propícia a corrosão. Japaratuba além de estar no sentido norte, próximo ao litoral, possui algumas pedreiras, áreas de constantes escavações próximas às colônias. Para os demais municípios, apesar de altas, as concentrações de ferro permaneceram abaixo dos valores determinados pelo CODEX, apresentando segurança para o consumo, de acordo com os valores encontrados em outras regiões do mundo [24-25]. Os demais minerais analisados estão em conformidade com os valores limites propostos pelo CODEX e a legislação brasileira.

Em comparação com trabalhos similares [9-10, 14], nos quais determina-se o conteúdo mineral do mel, foi possível observar que os valores das concentrações dos minerais analisados em méis estão próximos dos alcançados nestes trabalhos (Tabela 3).

Tabela 3: Teor dos principais minerais encontrados nos méis analisados.

\begin{tabular}{lccccc}
\hline & \multicolumn{5}{c}{ Média em mg/100g de mel } \\
\hline MINERAIS & Local a) & Local b) & Local c) & Local d) & Neste Estudo \\
Cálcio & $4,4-9,2$ & $3-31$ & $1,3-2,1$ & $13,05-1.024,7$ & $2-8,1$ \\
Potássio & $13,2-16,8$ & $40-3500$ & $11,4-35,8$ & $13,5-304,8$ & $26,6-129,9$ \\
Sódio & $0,0-7,6$ & $1,6-17$ & $6,4-9,1$ & $0,0-5,2$ & $1,4-17,4$ \\
Magnésio & $1,2-3,5$ & $0,7-13$ & $0,9-1,73$ & $6,50-73,7$ & $0,014-11,3$ \\
Ferro & $0,06-1,5$ & $0,003-4$ & $0,3-0,4$ & $0,9-1,7$ & $0,9-4,9$ \\
Manganês & $0,02-0,4$ & $0,002-2$ & $0,01-0,02$ & $0,04-0,2$ & $0,07-0,5$ \\
\hline
\end{tabular}

Fonte: a) [14]; b) [10]; c) [24] e d) [25].

As análises dos elementos-traço Cobalto (Co), Níquel (Ni) e Chumbo (Pb) apresentaram os perfis mostrados na Tabela 4.

\begin{tabular}{lccc} 
Tabela 4: Concentrações $\left(\mathrm{em} \mathrm{mg.} \mathrm{kg}^{-1}\right.$ ) dos elementos traço provenientes do Estado de \\
\cline { 2 - 5 } & $\mathbf{N}$ & $\mathbf{C o}$ & $\mathbf{P b}$ \\
\hline Poço Redondo & $0,03 \pm 0,01$ & $<\mathrm{LQ}$ & $0,22 \pm 0,04$ \\
Japaratuba & $0,06 \pm 0,02$ & $<\mathrm{LQ}$ & $0,16 \pm 0,23$ \\
Barra dos & $<\mathrm{LQ}$ & $<\mathrm{LQ}$ & $0,23 \pm 0,03$ \\
Coqueiros & & & \\
Porto da Folha & $<\mathrm{LQ}$ & $<\mathrm{LQ}$ & $0,08 \pm 0,01$ \\
\hline
\end{tabular}

Os resultados correspondem à média \pm desvio-padrão de cinco análises.

A legislação brasileira é contundente em relação aos limites aceitáveis de íons de metais em solos, águas e alimentos e não informando os limites críticos para todos os metais-traço em méis e existe uma carência de dados oficiais nacionais que subsidiem os legisladores e órgãos ambientais. Entre os metais estudados, apenas o chumbo apresenta concentrações máximas permitidas na Legislação $\left(0,3 \mathrm{mg} \mathrm{kg}^{-1}\right)$. Todos os teores de $\mathrm{Pb}$ foram identificados dentro do limite proposto na Instrução Normativa $n^{\circ} 11 / 12$ [22]. Em alguns países, como Dinamarca e Suíça, o chumbo tem seu limite máximo estabelecido em $1 \mathrm{mg} \mathrm{kg}^{-1}$ [26].

$\mathrm{O}$ elemento-traço Níquel (Ni) apresentou baixas concentrações nos munícipios de Poço Redondo e Japaratuba (0,22 e 0,16 mg kg${ }^{-1}$, respectivamente). Nos municípios de Barra dos Coqueiros e Porto da Folha, a presença de Ni foi detectada em teores abaixo do Limite de Quantificação $\left(0,01 \mathrm{mg} \mathrm{kg}^{-1}\right)$. Para o cobalto (Co) os resultados foram detectados em teores abaixo do Limite de Quantificação $\left(0,01 \mathrm{mg} \mathrm{kg}^{-1}\right)$ para as quatro áreas estudadas. 
Tendo em vista o limite máximo recomendado internacionalmente para o níquel ( $1 \mathrm{mg} \mathrm{Ni} / \mathrm{dia})$ [27], determinou-se que para o mel com maior teor em Ni $\left(0,06 \mathrm{mg} \mathrm{kg}^{-1}\right)$ seria necessário consumir cerca de 16,67 kg deste produto por dia para ultrapassar o valor máximo admissível. Desse modo, estes resultados indicam que o mel analisado não põe em risco à saúde dos consumidores, podendo este ser consumido como complemento na alimentação diária.

\section{CONCLUSÃO}

Os resultados das concentrações dos minerais encontrados em amostras de méis, das regiões em estudo, sugerem que o produto foi desenvolvido em área geograficamente pouco susceptível à contaminação. Vale ressaltar que a discrepância observada nos valores da concentração de $\mathrm{Pb}$ pode ser decorrente de fatores não correlacionados à extração e ao processamento do produto apícola, mas possivelmente a fatores como tipos de solo, clima e tipos de néctar existentes na região.

Os méis analisados apresentaram concentrações dos metais-traço Ni, Co e $\mathrm{Pb}$ dentro das faixas estabelecidas pelas legislações internacionais vigentes para alimentos e água. As concentrações referentes ao Ni e Co no mel podem contribuir cientificamente para a elaboração de legislações futuras, haja vista que as vigentes não estabelecem limites para concentração desses metais, com exceção do chumbo.

Além disso, a caracterização do conteúdo de minerais realizada nesta pesquisa gera resultados inéditos, os quais podem servir futuramente na elaboração de uma classificação dos méis de abelhas africanizadas obtidos em Sergipe a partir da correlação da composição destes com a origem geográfica do produto apícola.

Com base nos resultados obtidos, o mel produzido no Estado de Sergipe pode ser considerado de boa qualidade, tendo em vista que nenhum dos metais, potencialmente tóxicos, apresentaram concentrações acima do limite máximo recomendado.

\section{AGRADECIMENTOS}

Os autores agradecem ao CNPq e a CAPES pelo apoio concedido.

\section{REFERÊNCIAS BIBLIOGRÁFICAS}

1. Azeredo LC, Azeredo MAA, Dutra VML. Protein contents and physicochemical properties in honey samples of Apis mellifera of different floral origins. Food Chemistry. 2003;80(2):249-254. doi:10.1016/S0308-8146(02)00261-3

2. Campos GRC, Della-Modesta TJ, Silva KE, Baptista MF, Gomides RL, Godoy RL. Classification of honey as floral or honeydew honey. Ciênc. Tecnol. Aliment. 2003;23(1):1-5. doi:10.1590/S010120612003000100002

3. Ioannidou MD, Zachariadis GA, Anthemidis AN, Stratis JA. Direct determination of toxic trace metals in honey and sugars using inductively coupled plasma atomic emission spectrometry. Talanta. 2005; 65(1):92-97. doi:10.1016/j.talanta.2004.05.018

4. Pohl P. Determination of metal content in honey by atomic absorption and emission spectrometries. Trends in Analytical Chemistry. 2009;28(1):117-128. doi: 10.1016/j.trac.2008.09.015

5. Anklan E. A Review of the analytical methods to determine the geographical and botanical origin of honey. Food Chem. 1998;63(4):549-562. doi:10.1016/S0308-8146(98)00057-0

6. Jandrića Z, Haugheyb SA, Frewa RD, McCombc K, Galvin-Kingb P, Elliott CT, Cannavan A. Discrimination of honey of different floral origins by a combination of various chemical parameters. Food Chemistry. 2015;189:52-59. doi:10.1016/j.foodchem.2014.11.165

7. Porrini C, Sabatini AG, Girotti S, Ghini S, Medrzycki P, Grillenzoni F, Bortolotti L, Gattavecchia E, Celli G. Honey bees and bee products as monitors of the environmental contamination. Apiacta. 2003;38:63-70.

8. Miller-Ihli NJ. Atomic absorption and atomic emission sepectrometry for the determination of the trace element content of selected fruits consumed in the United States. J. Food Comp. Anal. 1996;9(4): 301311. doi:10.1006/jfca.1996.9997

9. Wiese H. Apicultura - novos tempos. Guaíba: Livraria Editora Agropecuária. 2000. 424p. 
10. Bogdanov S, Jurendic T, Sieber R, Gallmann P. Honey for nutrition and health: a review. J Am Coll Nutr. 2008 Dec;27(6):677-89.

11. Perugini M, Manera M, Grotta L, Abete MC, Tarasco R, Amorena M. Heavy metal (Hg, Cr, Cd, and $\mathrm{Pb}$ ) contamination in urban areas and wildlife reserves: honeybees as bioindicators. Biological trace element research. 2012;140(2):170-176.

12. Van der Steen JJM, de Kraker J, Grotenhuis T. Spatial and temporal variation of metal concentrations in adult honeybees (Apis mellifera L.). Environ. Monit. Assess. 2012;84(7):4119-4126. doi: 10.1007/s10661-011-2248-7

13. Fredes C, Montenegro G. Heavy metals and other trace elements contents in Chilean honey. Cien. Inv. Agr. 2006;33(1):50-58.

14. Baroni MV, Podio NS, Badini RG, Inga M, Ostera HA, Cagnoni M, Gautier EA, García PP, Hoogewerff J, Wunderlin DA. Linking soil, water, and honey composition to assess the geographical origin of argentinean honey by multielemental and isotopic analyses. J Agric Food Chem. 2015;63(18):4638-4645. doi: 10.1021/jf5060112

15. Aghamirlou HM, Khadem M, Rahmani A, Sadeghian M, Mahvi AM, Akbarzadeh A, Nazmara S. Heavy metals determination in honey samples using inductively coupled plasma-optical emission spectrometry. J Environ Health Science Engin. 2015;13:39. doi: 10.1186/s40201-015-0189-8

16. Anonymous. Codex Alimentarius commission Joint FAO/WHO. Food standart programme recommended European-regional standard for honey. 2002.

17. Anonymous. Codex Alimentarius commission Joint FAO/WHO. Norma general del CODEX para los contaminantes y las toxinas en los alimentos y piensos. 1995.

18. ANVISA. SVS/MS. Regulamento Técnico: "Princípios Gerais para o Estabelecimento de Níveis Máximos de Contaminantes Químicos em Alimentos" e seu Anexo: "Limites máximos de tolerância para contaminantes inorgânicos". Portaria no 685, de 27 de agosto de 1998. Assisted Extration for Sample Preparation and Spectroscopic Analytes

19. MERCOSUL/GMC/RES No 15/94. Regulamento técnico Mercosul de identidade e qualidade do mel. Buenos Aires. 1994.

20. Rappe RA, Lajus DL, Schreider MJ. Heavy metal impact on growth and leaf asymmetry of seagrass, Halophila ovalis. J Environ Chem Ecotoxicol. 2011;3(6):149-159.

21. Marchini LC, Moreti ACCC, Otsuk IP. Physicochemical composition of Apis mellifera L. honey samples from São Paulo state, Brazil. Quím Nova. 2007;30(7):1653-1657. doi: 10.1590/S010040422007000700029

22. BRASIL. Ministério da Agricultura e do Abastecimento. Gabinete do Ministro. Instrução Normativa $n^{\circ}$ 11, de 22 de maio de 2012. Aprova o Regulamento Técnico de Identidade e Qualidade do Mel. Diário Oficial [da] República Federativa do Brasil, Brasília, DF, 24 de Maio 2012. Seção 1, p. 07.

23. Leblebici Z, Aksoy A. Determination of Heavy metal in honey samples from Central Anatolia using plasma optical emission spectrofotometry (ICP-OES). Polish J. Environ. Stud. 2008. 17:101-107.

24. Baroni MV. Composition of honey from Córdoba (Argentina): Assessment of North/South provenance by chemometrics. Food Chemistry. 2009;114(2):727-733.

25. Garcia CAB, Garcia HL, Santos SF, Andrade ACS. Avaliação de metais em mel de abelhas comercializados no Município de Aracaju - SE. In: 32a Reunião Anual da Sociedade Brasileira de Química. 2009. Fortaleza - CE. CD da 34 Reunião Anual da Sociedade Brasileira de Química.

26. Bogdanov S. Contaminants of bee products. Apidologie. 2006; 37(1):1-18.

27. Food and Nutrition Board (2001), Dietary Reference Intakes for Vitamin A, Vitamin K, Arsenic, Boron, Chromium, Copper, Iodine, Iron, Manganese, Molybdenum, Nickel, Silicon, Vanadium, and Zinc. doi: $10.17226 / 10026$

28. Oliveira OS, Müller RCS, Dantas KGF, Alves CN, Vasconcelos MAM, Venturieri, GC. Ácidos fenólicos, flavonoides e atividade antioxidante em méis de Melipona fasciculata, M. flavolineata (Apidae, Meliponini) e Apis mellifera (Apidae, Apini) da Amazônia. Quím. Nova. 2012;35(9):17281732. doi: 10.1590/S0100-40422012000900005

29. United States Environmental Protection Agency - USEPA Microwave assisted acid digestion of sediments sludge, soils, and oils. EPA SW 846 3051a. 30p, 2007). available in: http://www.epa.gov/epawaste/hazard/testmethods/sw846/pdfs/3051a.pdf 